\title{
Pengujian Black Box pada Aplikasi Penjualan Berbasis Website dengan PHP MySQL Kedai Kopi.Net Menggunakan Teknik Boundary Value Analysis
}

\author{
Daniel Dadan Wiguna Soejono ${ }^{1}$, Dedek Rahmat Candra ${ }^{2}$, Dedi Rosandi ${ }^{3}$, Rizky Rahma \\ Putra $^{4}$, Yoga Nurfaidzin 5 , Hendri Ardiansyah ${ }^{6}$
}

Teknik Informatika, Universitas Pamulang, Tangerang Selatan, Indonesia, 15416

e-mail:1dnldws15@gmail.com, ${ }^{2}$ dedekrahmatcandra@gmail.com, ${ }^{3}$ dedirosandi@yahoo.com,

4riskyrahma83@gmail.com, ${ }^{5}$ yoganf29@gmail.com, ${ }^{6}$ dosen00832@unpam.ac.id

Submitted Date: December $27^{\text {th }}, 2019$

Revised Date: January $13^{\text {th }}, 2020$

\author{
Reviewed Date: January $09^{\text {th }}, 2020$ \\ Accepted Date: April 29 $9^{\text {th }}, 2020$
}

\begin{abstract}
Kopi.Net shop application is an applications created and designed in the hope that it can provide information about every product in Kopi.Net shot online, but it cannot be used in general because there are still problems so testing needs to be done in order to reduce the level of failure or error which can cause losses to the store's selling activities. Applications that have already been designed must be tested first, in the coffee shop application testing using the boundary value analysis and validation method, validation is a process to the check whether the application has reached the desired application standard. In proof, a data that is not accordance with the database. As an example, stock data will become uncertain or exceed the capacity created. That way it can cause harm to the coffee shop application. Therefore, it requires repairing and testing data validation more accurately. So that it can help the owner of the coffee shop application in accurate data stock data. Testing applications that are designed must be tested before the application is made must go through testing to ensure applications that have been made must pass through the stages of testing so that the application has good quality. Testing can be said to be good if it finds a program failure that is difficult to find. There are many black box testing methods, on this occasion the examiner uses the boundary value analysis method. This boundary value analysis method tests the number of maximum limits and the number of suitable minimum limits and find valid result. Testing is quite maximum for the Kedai Kopi.Net application. The initial process in testing this application is to provide a definition of what will be tested, create a test framework, and choose test materials. And ensure the maximum and minimum amount in accordance with the structure of the database, as well as making the result of the documented test results and can draw conclusions based on test result. Kedai Kopi.Net application can be used after the test is complete and can be used well, and is said to be successful if all errors can be known and corrected before general use.
\end{abstract}

Keywords: Information System; Sales; Testing; Black Box: Boundary Value Analysis

\section{Abstrak}

Aplikasi Kedai Kopi.Net ialah aplikasi yang dibuat dan dirancang dengan harapan dapat memberikan informasi tentang setiap produk yang ada di Kedai Kopi.Net secara online, tetapi belum dapat gunakan secara umum karena masih terdapat permasalahan sehingga perlu dilakukan pengujian agar dapat mengurangi tingkat kegagalan atau kesalahan yang dapat menimbulkan kerugian terhadap kegiatan penjualan kedai tersebut. Aplikasi yang sudah selesai dirancang harus diuji terlebih dahulu, dalam pengujian aplikasi Kedai Kopi.Net mengunakan metode boundary value analysis serta validasi, validasi merupakan sebuah proses untuk memeriksa apakah aplikasi tersebut sudah mencapai standar aplikasi yang diinginkan. Dalam pembuktian, sebuah data yang tidak sesuai dengan standar yang diinginkan maka data tersebut tidak sesuai dengan basisdata. Dapat dicontohkan seperti data stok barang akan menjadi tidak pasti atau melebihi kapasitas yang dibuat. Dengan seperti itu dapat menimbulkan kerugian pada aplikasi Kedai Kopi.Net. Maka dari itu, memerlukan perbaikan dan pengujian data validasi yang lebih akurat. Sehingga dapat membantu pemilik aplikasi Kedai Kopi.Net dalam 
mengakuratkan data stok barang. Pengujian aplikasi yang dirancang tersebut harus diuji terlebih dahulu aplikasi yang dibuat harus melalui pengujian untuk memastikan Aplikasi yang sudah dibuat harus melewati tahapan-tahapan pengujian agar aplikasi tersebut memiliki kualitas yang bagus. Pengujian dapat dikatakan bagus bila menemukan kegagalan program yang susah untuk ditemukan.Terdapat banyak metode-metode pengujian black box, dalam kesempatan ini penguji mengunakan metode boundary value analysis. Metode boundary value analysis ini menguji banyaknya batas maksimum dan banyaknya batas minimum yang cocok dan menemukan hasil yang valid. Pengujian cukup maksimal untuk aplikasi Kedai Kopi.Net. Proses awal dalam pengujian aplikasi ini adalah memberikan definisi apa yang akan diuji, membuat kerangka uji, dan memilih bahan uji. Dan memastikan jumlah maksimum dan minimum sesuai dengan struktur basis data, serta membuat hasil dokumtasi hasil uji dan dapat menarik kesimpulan yang dihasilkan berdasarkan hasil uji. Aplikasi Kedai Kopi.Net dapat digunak setelah pengujian selesai dan dapat digunakan dengan bagus, dan dikatakan berhasil apabila semua kesalahan sudah dapat diketahui dan diperbaiki sebelum digunakan secara umum.

Kata kunci: Sistem Informasi; Penjualan; Pengujian; Black Box; Boundery Value Analysis

\section{Pendahuluan}

Aplikasi Kedai Kopi.Net merupakan sebuah sistem yang dirancang dengan harapan dapat memberikan informasi tentang setiap produk yang ada di Kedai Kopi.Net secara online. Aplikasi web akan tumbuh dan meningkat penggunaannya, membuat kompleksitasnya pun semakin meningkat, sehingga menciptakan permintaan yang besar untuk teknik dan alat yang memastikan teruji kehandalannya. Hasil dari penelitian ini adalah pilihan metode dan alat pengujian yang digunakan untuk melakukan pengujian terhadap aplikasi Kedai Kopi.Net (Hidayat \& Muttaqin).

Pengujian aplikasi Kedai Kopi.Net untuk menemukan kesalahan dan error pada pengembangan aplikasi ini, agar aplikasi menjadi lebih efektif dan efisiensinya terjaga. Kualitas aplikasi "Kedai Kopi.Net" tergantung pada kepuasan dan kenyamanan pembeli serta kualitas aplikasi harus dapat selalu dijaga agar aplikasi ini dapat bersaing dengan aplikasi lain serta memperkecil biaya agar tidak banyak pembeli karena kegagalan pemasaran dan produksinya (Zuriati, Widjayanti, Sitanggang, \& Buowo, 2018).

Survei yang dilakukannya mengenai metode black box menunjukkan bahwa terdapat pendekatan pengujian dan alat yang berbeda untuk metode black box dari aplikasi database. Pada pengujian aplikasi dengan Teknik black box dilakukan hanya mengambil hasil eksekusi melalui data uji dan memeriksa fungsional dari perangkat lunak (Krismadi, et al., 2019). Pendekatan juga melibatkan metode lain yang berbeda yang dibuat pada rencana eksekusi bahwa sistem manajemen database yang mendasar berasal untuk setiap pernyataan SQL
(Cholifah, Yulianingsih, \& Sagita, 2018).

Pengujian black box, memiliki beberapa cara diantaranya ialah perancangan tujuan yang akan dicapai dengan jelas, menyediakan bahan pengujian untuk menunjang program dari sistem aplikasi terstruktur dengan benar dan menganalisa aplikasi apakah masih terdapat kesalahan atau tidak. Serta pengujian dikatakan bagus apabila sudah tidak ditemukanya kesalahan dan kegagalan pada aplikasi yang sudah dirancang (Sutanto, Utomo, \& Perbawa, 2018)

Hasil uji black box untuk mengetahui setiap fungsi yang beroperasi sesuai dengan tugasnya masing-masing. Pengujian yang dilakukan berfokus pada menu login, menu home, menu pencarian dan menu pemesanan, sehingga sistem dikatakan berhasil apabila sudah tidak ada lagi terdapat kegagalan data yang dimasukkan setelah dieksekusi. Dengan demikian berdasarkan pengujian yang dilakukan dapat diketahui di mana letak kesalahan dan kekurangan apabila didapat pada sistem aplikasi ini sebelum digunakan oleh penguna baik admin atau customer (Safitri \& Pramudita, 2018). Hel ini menunjukkan pentingnya melakukan pengujian untuk mengurangi terjadinya kesalahan yang merugikan ketika aplikasi digunakan (Ningrum, Suherman, Aryanti, Prasetya, \& Saifudin, 2019).

\section{Metodologi}

Aplikasi Kedai Kopi.Net merupakan sistem informasi yang dirancang dengan harapan dapat memberikan informasi tentang setiap produk yang ada di Kedai Kopi.Net secara online. Sistem informasi adalah kumpulan dari sub-sub sistem yang saling 
terintegrasi dan berkolaborasi untuk menyelesaikan masalah tertentu dengan cara mengolah data sehingga memiliki nilai tambah dan bermanfaat bagi pengguna (Taufiq, 2018).

Pengujian merupakan suatu proses pelaksanaan program yang bertujuan menemukan kesalahan dan memperbaikinya sehingga sistem dikatakan layak untuk digunakan (Nurudin, Jayanti, Saputro, Saputra, \& Yulianti, 2019). Pengujian aplikasi sangatlah penting untuk menghindari terjadinya kesalahan saat aplikasi sedang digunakan dan sering terjadinya kegagalan mengakibatkan tidak nyamanya penguna dalam mengunakan aplikasi tersebut.

Selain itu suatu proses pengujian membutuhkan tujuan akhir yang dapat dinilai sehingga pihak tester bisa berhenti melakukan suatu testing ketika tujuan-tujuan itu tercapai (Krismadi, et al., 2019). Jika semua fase pengujian sudah dilaksanakan dan tidak ditemukan kesalahan, maka pengujian dianggap cukup.

Pengujian aplikasi Kedai Kopi.Net mengunakan metode boundary value analysis untuk keakuratan sebuah data dengan sistem aplikasi yang sudah dirancang dengan nilai skala serta menilai apakah aplikasi tersebut dapat digunakan dengan baik. Pengujian black box agar ditemukan kesalahan dan kegagalan dari aplikasi yang sudah dibuat dan dikembangkan sehingga kegagalan dan kesalahan dapat segera dierbaiki, penguji akan terus melakukan pengujian berulang-ulang jika dalam tahap pengujian ditemukan kesalahan (Komarudin, 2016)

Berikut ini beberapa teori pendukung yang digunakan dalam pengujian aplikasi Kedai Kopi.Net:

1. Metode Boundary Value Analysis

Pengujian aplikasi Kedai Kopi.Net mengunakan metode boundary value analysis, Metode ini dikenal dengan menguji banyaknya batas maksimum dan banyaknya batas minimum yang cocok dan menemukan hasil yang valid. Berikut beberapa dasar dari metode boundary value analysis:

1. Boundary value analysis lebih memfokuskan kepada batas nilai maksimum dan batas nilai minimum yang sulit untuk ditemukan kegagalanya.

2. Boundary value analysis memusatkan pencarian kesalahan dan kegagalan program lebih kepada nilai batas.

3. Boundary value analysis melakukan pengujian dengan nilai data yang terstruktur dengan batasan maksimum dan minimum (Andriansyah, 2018)

Boundary value analysis ialah salah satu metode pengujian black bo memulai pengujian dengan batasan nilai maksimum dan batasan nilai minimum. Berikut definisi pokok dari metode boundary value analysis:

1. Boundary value analysis lebih mencermati kepada jumlah angka dan huruf yang di masukkan dan hasil yang dikeluarkan dari data yang dimasukkan tersebut.

2. Boundary value analysis serta penyesuaikan nilai dengan nilai maksimum dan nilai minimum (Hidayat \& Muttaqin)

Selanjutnya contoh dari metode boundary value analysis untuk kemudian ditemukanya nilai batasan maksimum dan minimum:

$$
0 \leq \text { angka } \leq 9 \text { serta } \mathrm{A} \leq \text { huruf } \leq \mathrm{Z}
$$

Dari contoh di atas maka dapat didefinisikan bahwa boundary value analysis lebih berfokus melakukan pengujian dengan mengamati dan menguji data nilai batas maksimum dan nilai batas minimum. (Andriansyah, 2018)

2. Tampilan Antarmuka

Tampilan antarmuka sering disebut dengan tampilan dari aplikasi yang sudah dibuat agar customer dapat memahami dan mengunakan aplikasi tersebut dengan baik dan benar serta menjaga kenyamanan customer dalam mengunakan aplikasi tersebut. Dan nantinya penguna dapat mengetahui dengan mudah apa saja yang harus dilakukan dalam mengunakan aplikasi.

Berikut adalah tampilan aplikasi Kedai Kopi.Net berbasis web :

\section{a. Tampilan Login User}

Halaman login adalah halaman utama ketika membuka aplikasi Kedai Kopi.Net sebelum kehalaman menu utama. Pada halaman login kita akan diwajibkan untuk memasukkan nama dan kata sandi seperti data terlebih dahulu untuk dapat masuk ke laman utama. 


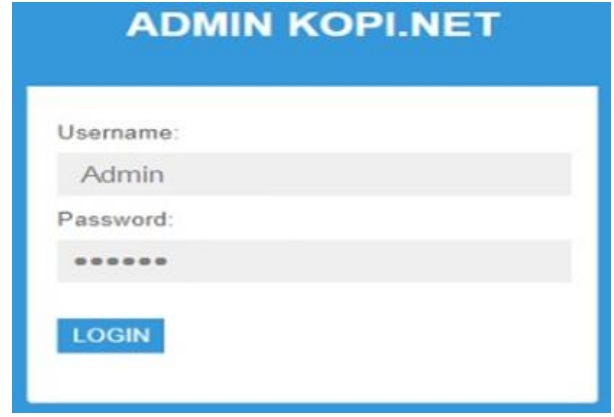

Gambar 1. Tampilan Login User

\section{b. Tampilan Halaman Utama}

Setelah masuk halaman utama akan ada pilihan menu untuk mengelola setiap data. Pada halaman menu utama admin dapat mengelola semua data atau hak akses diberikan semua kepada admin, diantaranya tambah produk dan menu pemesanan.

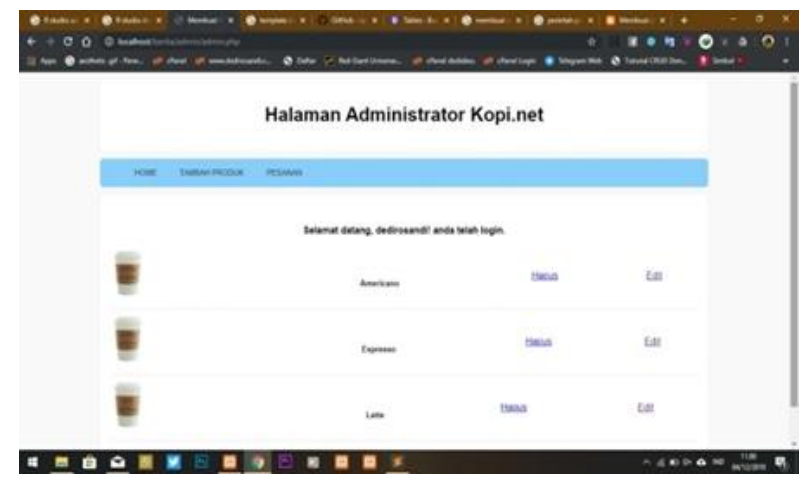

Gambar 2. Tampilan Halaman Utama

c. Tampilan Menu Tambah Barang

Di dalam tampilan ini terdapat form tambah barang dan tempat mengelola semua item dan nama-nama barang, seperti menyimpan data barang terbaru, mengubah data barang dan mengubah atau menambahkan gambar barang.

Tombol choose file untuk menambahkan gambar barang terbaru, tombol simpan untuk menyimpan maupun data yang sudah diubah dan tombol logout jika hendak keluar dari form tambah barang.

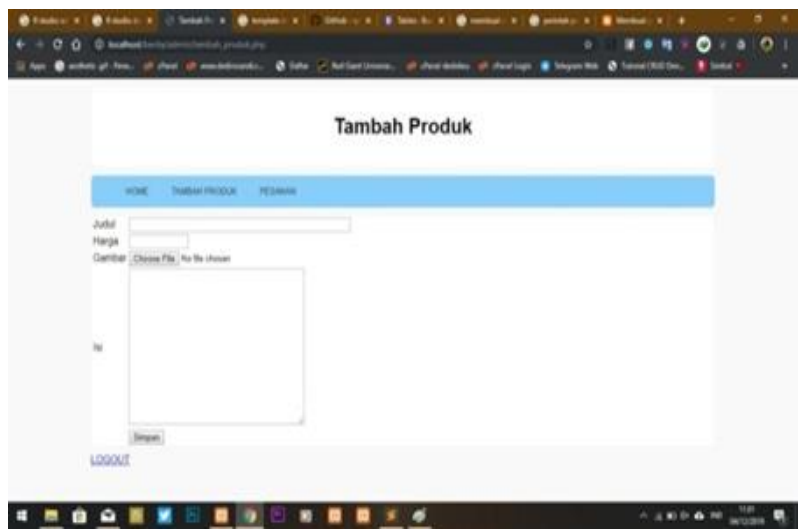

Gambar 3. Tampilan Menu Tambah Barang

\section{Hasil Dan Pembahasan}

Sebelum aplikasi ini digunakan, maka terlebih dahulu harus diuji agar bebas dari kesalahan-kesalahan yang mungkin terjadi dan memastikan semua elemen-elemen berjalan dengan baik.

Dari Gambar di atas maka dapat dilakukan pengujian pada aplikasi Kedai Kopi.Net berbasis web seperti pada tabel-tabel berikut ini:

a. Pegujian Login

Tabel 1. Tabel Pengujian Login

\begin{tabular}{|l|l|l|c|}
\hline \multicolumn{1}{|c|}{ Skenario Pengujian } & Hasil yang Diharapkan & \multicolumn{1}{|c|}{ Hasil Pengujian } & Kesimpulan \\
\hline $\begin{array}{l}\text { Mengosongkan } \text { username dan } \\
\text { password lalu klik tombol login }\end{array}$ & Muncul alern login gagal & $\begin{array}{l}\text { Muncul alern login } \\
\text { gagal }\end{array}$ & Valid \\
\hline $\begin{array}{l}\text { Mengosongkan salah satu field, baik } \\
\text { username atau password }\end{array}$ & Muncul alern login gagal & $\begin{array}{l}\text { Muncul alern login } \\
\text { gagal }\end{array}$ & Valid \\
\hline $\begin{array}{l}\text { Mengisi username dan password } \\
\text { dengan benar }\end{array}$ & $\begin{array}{l}\text { Login berhasil dan } \\
\text { masuk ke menu utama }\end{array}$ & $\begin{array}{l}\text { Login berhasil dan } \\
\text { masuk ke menu utama }\end{array}$ & Valid \\
\hline
\end{tabular}

b. Pengujian Menu Tambah Produk 
Tabel 2. Tabel Pengujian Tambah Produk

\begin{tabular}{|l|l|l|c|}
\hline \multicolumn{1}{|c|}{ Skenario Pengujian } & Hasil yang Diharapkan & \multicolumn{1}{c|}{ Hasil Pengujian } & Kesimpulan \\
\hline Klik tombol tambah produk & $\begin{array}{l}\text { Masuk ke tampilan form } \\
\text { tambah produk }\end{array}$ & $\begin{array}{l}\text { Masuk ke tampilan form } \\
\text { tambah produk }\end{array}$ & Valid \\
\hline $\begin{array}{l}\text { Klik tombol choose file, lalu } \\
\text { memasukkan gambar dan klik ok }\end{array}$ & $\begin{array}{l}\text { Gambar berhasil } \\
\text { dimasukkan, tampilan } \\
\text { kembali ke menu form } \\
\text { tambah produk }\end{array}$ & $\begin{array}{l}\text { Gambar berhasil } \\
\text { dimasukkan, tampilan } \\
\text { kembali ke menu form } \\
\text { tambah produk }\end{array}$ & Valid \\
\hline $\begin{array}{l}\text { Input semua data form lalu klik } \\
\text { simpan }\end{array}$ & $\begin{array}{l}\text { Data berhasil di simpan, } \\
\text { tampilan kembali ke menu } \\
\text { utama }\end{array}$ & $\begin{array}{l}\text { Data berhasil di simpan, } \\
\text { tampilan kembali ke } \\
\text { menu utama }\end{array}$ & Valid \\
\hline $\begin{array}{l}\text { Mengosongkan salah satu field dalam } \\
\text { pengisian data form lalu klik simpan }\end{array}$ & $\begin{array}{l}\text { Muncul pesan please field } \\
\text { out this field }\end{array}$ & $\begin{array}{l}\text { Muncul pesan please field } \\
\text { out this field }\end{array}$ & Valid \\
\hline $\begin{array}{l}\text { Mengisi judul produk dengan judul } \\
\text { yang sama }\end{array}$ & $\begin{array}{l}\text { Muncul alert data yang anda } \\
\text { masukkan sudah ada }\end{array}$ & $\begin{array}{l}\text { Muncul alert data yang } \\
\text { anda masukkan sudah ada }\end{array}$ & Valid \\
\hline
\end{tabular}

\section{Kesimpulan}

Semakin penting dan dibutuhkanya suatu informasi yang cepat, tepat dan akurat, mengharuskan suatu unit kerja untuk dapat memberikan informasi yang baik yaitu dengan menggunakan database yang terkomputerisasi. Berdasarkan uji dapat ditarik kesimpulan. Aplikasi penjualan Kedai Kopi.Net Berbasis Web ini bertujuan untuk memudahkan pembeli dan pegawai staf kasir dalam mengetahui stok kopi yang tersedia.

\section{Saran}

Saran pengembangan adalah dengan menambahkan detail data laba dan rugi pada saat memasukkan laporan, sehingga kemungkinan penguna untuk melakukan kesalahan menjadi lebih kecil. Pengembangan juga bisa dilakukan dengan menambahkan menu backup basis data sebagai salah satu strategi keamanan data.

\section{References}

Andriansyah, D. (2018). Pengujian Kotak Hitam Boundary Value Analysis pada Sistem Informasi Manajemen Konseling Tugas Akhir. Indonesian Journal on Networking and Security Vol 7 No 1, 13-18.

Cholifah, W. N., Yulianingsih, \& Sagita, S. M. (2018, Desember). Pengujian Black Box Testing Pada Aplikasi Action And Strategi Berbasis Android Dengan Technology PHONEGAP. Jurnal String Vol. 3 No.2, 206-210.

Hidayat, T., \& Muttaqin, M. (2018, April). Pengujian Sistem Informasi Pendaftaran dan Pembayaran Wisuda Online Mengunakan Black Box Testing Dengan Metode Equivalence Pertitioning dan Boundary
Value Analysis. Jurnal Teknik Informatika UNIS Vol.6 No.1, 25-29.

Komarudin, M. (2016). Pengujian Perangkat Lunak Metode Black-Box Berbasis Equivalence Partitions pada Aplikasi Sistem Informasi Sekolah. Jurnal Mikrotik Vol 06 No 03, 118.

Krismadi, A., Lestari, A. F., Pitriyah, A., Mardangga, I. W., Astuti, M., \& Saifudin, A. (2019).

Pengujian Black Box berbasis Equivalence Partitions pada Aplikasi Seleksi Promosi Kenaikan Jabatan. Jurnal Teknologi Sistem Informasi dan Aplikasi, 2(4), 155-161.

Ningrum, F. C., Suherman, D., Aryanti, S., Prasetya, H. A., \& Saifudin, A. (2019). Pengujian Black Box pada Aplikasi Sistem Seleksi Sales Terbaik Menggunakan Teknik Equivalence Partitions. Jurnal Informatika Universitas Pamulang, 4(4), 125-130.

Safitri, N., \& Pramudita, R. (2018). Pengujian Black Box Menggunakan Metode Cause Effect Relationship Testing. Information System For Educators And Professionals Vol 3 No 1, 101-110.

Sutanto, Y., Utomo, A., \& Perbawa, D. S. (2018). Pengujian Aplikasi Website Menggunakan Black Box Testing Boundary Value Analysis (Studi Kasus : Aplikasi website praktekdokter). Jurnal SAINSTECH Politeknik Indonusa Surakarta Vol 5 No 2, 52-57.

Taufiq, R. (2018). Pengantar Sistem Informasi. Jakarta: Mitra Wacana Media.

Zuriati, Widjayanti, D. K., Sitanggang, I. S., \& Buowo, A. (2018, Desember). Teknik Pengujian Boundary Value Analysis Pada Aplikasi Learning Management System Polinela. Jurnal TAM (Technology Acceptance Model) Volume 9 No.2, 85-92. 